\title{
Title
}

\section{Proteomic analysis of calcium-enriched sol-gel biomaterials}

\section{Authors}

F. Romero-Gavilán ${ }^{1 *}$, N. Araujo-Gomes ${ }^{1 * \&}$, A. Cerqueira ${ }^{2}$, I. García-Arnáez ${ }^{3}$, C. Martínez-Ramos $^{2}$, M. Azkargorta ${ }^{4}$, I. Iloro ${ }^{4}$, F. Elortza ${ }^{4}$, M. Gurruchaga ${ }^{3}$, J. Suay ${ }^{1}$, I. Goñi ${ }^{3}$

${ }^{1}$ Departamento de Ingeniería de Sistemas Industriales y Diseño. Universitat Jaume I, Av. Vicent-Sos Baynat s/n. Castellón 12071. Spain.

${ }^{2}$ Department of Medicine. Universitat Jaume I, Av. Vicent-Sos Baynat s/n. Castellón 12071. Spain.

${ }^{3}$ Facultad de Ciencias Químicas. Universidad del País Vasco. P. M. de Lardizábal, 3. San Sebastián 20018. Spain.

${ }^{4}$ Proteomics Platform, CIC bioGUNE, CIBERehd, ProteoRed-ISCIII, Bizkaia Science and Technology Park, 48160 Derio, Spain.

${ }^{*}$ Co-authorship.

${ }^{\&}$ Corresponding author: Nuno Araújo-Gomes

e-mail: araujoda@uji.es

Phone: +34 964388773 


\begin{abstract}
Calcium is an element widely used in the development of biomaterials for bone tissue engineering as it plays important roles in bone metabolism and blood coagulation. The $\mathrm{Ca}$ ions can condition the microenvironment at the tissue-material interface, affecting the protein deposition process and cell responses. The aim of this study was to analyze the changes in the patterns of protein adsorption on the silica hybrid biomaterials supplemented with different amounts of $\mathrm{CaCl}_{2}$, which can function as release vehicles. This characterization was carried out by incubating the Ca-biomaterials with human serum. LC-MS/MS analysis was used to characterize the adsorbed protein layers and compile a list of proteins whose affinity for the surfaces might depend on the $\mathrm{CaCl}_{2}$ content. The attachment of pro- and anti-clotting proteins, such as THRB, ANT3, and PROC, increased significantly on the Ca-materials. Similarly, VTNC and APOE, proteins directly involved on osteogenic processes, attached preferentially to these surfaces. In order to assess correlations with the proteomic data, these formulations were tested in vitro regarding their osteogenic and inflammatory potential, employing MC3T3-E1 and RAW 264.7 cell lines, respectively. The results confirmed a Ca dose-dependent osteogenic and inflammatory behavior of the materials employed, in accordance with the protein attachment patterns.
\end{abstract}

\title{
Keywords:
}

Prothrombin, apolipoprotein E, blood clotting, vitronectin, bone regeneration 


\section{Introduction}

Calcium, one of the most abundant elements in the human body, forms very versatile ions and is critically involved in many processes in living organisms [1]. The bone tissue is the greatest reservoir of calcium in the body, where this element is one of the main components of biological apatite $\left(\mathrm{Ca}_{10}\left(\mathrm{PO}_{4}, \mathrm{CO}_{3}\right) 6 \mathrm{OH}_{2}\right)$, the inorganic phase of bones [2]. Not surprisingly, this element is important in bone remodeling and recovery [3].

Extracellular calcium plays a crucial role in bone metabolism; it upregulates the calciumsensing receptor (CaSR), activating intracellular signaling pathways involved in the regulation of bone cell activity in vitro and in vivo [4]. The activation of Ca channels has been associated with an increase in the expression of growth factors such as IGF-I and IGF-II [5]. Increasing the levels of extracellular calcium elevates the expression of OCN, OPN, RUNX2, and BMP-2 genes in vitro [6] and can promote osteoblast proliferation, differentiation, and extracellular matrix mineralization [7].

Silica hybrid biomaterials have been proposed as potential controlled release vehicles [8]. These materials display important bioactive, biocompatible, and biodegradable properties, and can be synthesized using the sol-gel process with organically modified alkoxysilanes as precursors [9]. Moreover, the sol-gel technology allows modification of their properties (for example, their degradation rates). The resulting materials, with their strong adhesion properties, can be applied as coatings on metal surfaces [10]. They are now increasingly used in biomedical applications, in particular for implant surface functionalization $[11,12]$. Some researchers have employed this vehicle type to develop new Ca-releasing biomaterials [13-16].

The specific physico-chemical properties of biomaterials ultimately affect the organismmaterial interactions. The microenvironment formed immediately after the implantation 
of biomaterials conditions their interactions with various molecules such as the bodily fluid proteins and, consequently, affects the characteristics of the protein layer deposited onto the material surface [17]. This protein deposition is a complex process ruled by the Vroman effect, based on the competitive displacement of already absorbed proteins by other proteins with higher affinity to the material surface [18]. Protein deposition depends on the surface properties such as wettability, roughness, and charge [19], determined by the chemical composition of the surface. The properties of the adsorbed protein layer play a pivotal role in the initiation and progress of biological processes occurring after implantation [20]. Apart from the initial activation of immune defenses in response to the foreign body [21, 22], the constitution of the layer is likely to affect other processes, such as coagulation, fibrinolysis, and even the bone cell response in the earlier stages of osteogenesis [23]. Coagulation plays a key role in the bone healing process; the blood clot formation is one of its incipient steps. Thus, a correct biochemical cascade initiation might be a crucial step in this process, regulating clot formation and subsequent fibrin architecture [24].

Here, different hybrid sol-gel networks with increasing amounts of $\mathrm{CaCl}_{2}$ were applied as coatings onto titanium surfaces. The proteomic analysis of human serum proteins deposited onto these Ca-enriched surfaces was performed using mass spectrometry (LCMS/MS). This allowed us to obtain protein adsorption patterns for the materials with different $\mathrm{CaCl}_{2}$ content. The effects of $\mathrm{Ca}$ introduction on the osteogenic potential of materials and their interactions with immune cells were also assessed. The main objective of the study was to evaluate the effects of calcium on biological responses (inflammation, coagulation, fibrinolysis, and osteogenesis) from the proteomic perspective. 


\section{Materials and methods}

\subsection{Sol-gel synthesis and coating preparation}

Grade-4 Ti discs (12-mm diameter, 1-mm thick) with the same commercial sandblasted acid-etched treatment explained in [21], and were employed as coating substrate. The solgel route was followed to obtain hybrid coatings. Silica hybrid materials enriched with $\mathrm{Ca}$ were obtained using the sol-gel process, with the alkoxysilanes methyltrimethoxysilane, 3-(glycidoxypropyl)-trimethoxysilane, and tetraethyl orthosilicate (Sigma-Aldrich, St. Louis, MO, USA). The network types selected as Carelease vehicles contained 35\%, 35\%, and 30\% (molar percentages) of these precursors, respectively. The base material, 35M35G30T, was chosen based on previous studies [10]. The Ca percentages applied to the coating (\%) are shown in Table 1.

Table 1. Chemical compositions of Ca-enriched materials expressed as $\mathrm{CaCl}_{2}$ weight percentage.

\begin{tabular}{|c|c|c|}
\hline Reference & Sol-gel base network & $\mathbf{C a C l}_{\mathbf{2}}(\boldsymbol{\%})$ \\
\hline $0 \mathrm{Ca}$ & $35 \mathrm{M} 35 \mathrm{G} 30 \mathrm{~T}$ & 0 \\
\hline $0.5 \mathrm{Ca}$ & $35 \mathrm{M} 35 \mathrm{G} 30 \mathrm{~T}$ & 0.5 \\
\hline $1 \mathrm{Ca}$ & $35 \mathrm{M} 35 \mathrm{G} 30 \mathrm{~T}$ & 1 \\
\hline $2.5 \mathrm{Ca}$ & $35 \mathrm{M} 35 \mathrm{G} 30 \mathrm{~T}$ & 5 \\
\hline $5 \mathrm{Ca}$ & $35 \mathrm{M} 35 \mathrm{G} 30 \mathrm{~T}$ & 7.5 \\
\hline $7.5 \mathrm{Ca}$ & $35 \mathrm{M} 35 \mathrm{G} 30 \mathrm{~T}$ & \\
\hline
\end{tabular}

In the synthesis, 2-Propanol (Sigma-Aldrich) was used as a solvent at a volume ratio (alcohol:siloxane) of 1:1. Hydrolysis of alkoxysilanes was carried out by adding (at a rate of 1 drop s $^{-1}$ ) the corresponding stoichiometric amount of $0.1 \mathrm{M} \mathrm{HNO}_{3}$ (Panreac, Barcelona, Spain). First, however, the required quantities of calcium chloride (SigmaAldrich) were dissolved in this solution. The preparations were kept for $1 \mathrm{~h}$ under stirring followed by $1 \mathrm{~h}$ at rest. The samples were prepared immediately afterward, SAE-titanium 
was used as the substrate for the sol-gel coatings. The coatings were made employing a dip-coater (KSV DC; KSV NIMA, Espoo, Finland). Discs were immersed in the sol-gel solutions at a speed of $60 \mathrm{~cm} \mathrm{~min}^{-1}$, left immersed for one minute, and removed at a 100 $\mathrm{cm} \mathrm{min}^{-1}$. In order to study $\mathrm{Ca}$ liberation, the coatings were applied using flow-coating onto glass slides, which were previously cleaned in an ultrasonic bath (Sonoplus HD 3200) for $20 \mathrm{~min}$ at $30 \mathrm{~W}$ with nitric acid solution at $25 \%$ volume. Finally, all of the samples were cured for $2 \mathrm{~h}$ at $80^{\circ} \mathrm{C}$.

\subsection{Physicochemical characterization}

The surface topography of samples was characterized using scanning electron microscopy (SEM), employing the Leica-Zeiss LEO equipment under vacuum (Leica, Wetzlar, Germany). The materials were submitted to platinum sputtering to increase their conductivity for the SEM observations. An optical profilometer (interferometric and confocal) PLm2300 (Sensofar, Barcelona, Spain) was used to determine the roughness. Three discs of each type were tested. Three measurements were performed for each disc to obtain the average values of the Ra parameter. The contact angle was measured using an automatic contact angle meter OCA 20 (DataPhysics Instruments, Filderstadt, Germany). An aliquot of $10 \mu \mathrm{L}$ of ultrapure water was deposited on the disc surfaces at a dosing rate of $27.5 \mu \mathrm{L} \mathrm{s}^{-1}$ at room temperature. Contact angles were determined using the SCA 20 software (DataPhysics Instruments). Six discs of each material were studied, after depositing two drops on each disc. In order to study the Ca release during time, it was employed the inductively coupled plasma mass spectrometer Agilent 7700 Series ICPMS. Ca release was assessed using samples submerged in $\mathrm{ddH}_{2} \mathrm{O}$ at $37{ }^{\circ} \mathrm{C}$ for 2 weeks. Aliquots of 500 $\mu \mathrm{L}$ were taken after 1, 7, 14 and 28 days of immersion. Each data point was found by measuring three independent samples of each condition. 


\subsection{In vitro assays}

\subsubsection{Cell culture}

The cell lines MC3T3-E1 (mouse calvaria osteosarcoma cell line) and RAW 264.7 (mouse murine macrophage cell line) were employed and cultured on the distinct coatings at a concentration of $1 \times 10^{4}$ cells well-1, on 24-well culture plates (Thermo Fisher Scientific, Waltham, MA, USA). Culture medium for both cell lines was composed of DMEM w/phenol red (Gibco-Life Technologies, Grand Island, NY, USA), 1\% of 100x penicillin/streptomycin (Biowest Inc., Riverside, KS, USA) and $10 \%$ of fetal bovine serum (FBS) (Gibco-Life Technologies). Following incubation for 24 hours at a temperature of $37^{\circ} \mathrm{C}$ with $95 \%$ humidity and $5 \% \mathrm{CO} 2$, the medium of the osteoblastic cell-line was replaced by an osteogenic medium (DMEM w/phenol red $1 \times, 1 \%$ penicillin/streptomycin, $10 \% \mathrm{FBS}, 1 \%$ ascorbic acid (5 mg mL-1) and $0.21 \% \beta$ glycerol phosphate) followed by incubation at the initial conditions. At every 48 hours the osteogenic medium was renewed. These cells underwent on these conditions 7 and 14 days to be allowed to differentiate to proceed to RNA isolation.

RAW 264.7 macrophages cell medium was harvested at 2 and 4 days of culture to assess TNF- $\alpha$ release using ELISA. Cells at the same concentration $\left(1 \times 10^{4}\right.$ cells $)$ incubated without biomaterials were used as a control of culture conditions.

\subsubsection{RNA isolation and cDNA synthesis}

Total RNA was prepared from both cell lines grown on the sol-gel coated titanium discs, using Qiagen RNeasy Mini kit (Qiagen, Hilden, Germany), following digestion with DNaseI (Qiagen), according to the manufacturer's instructions. $1 \mu \mathrm{g}$ of total RNA of each sample was transcripted onto cDNA with PrimeScript RT Reagent Kit (Perfect Real 
Time) (TAKARA Bio Inc., Shiga, Japan). The product cDNA was diluted in DNase-free water to be used for qRT-PCR.

\subsubsection{Quantitative real-time PCR}

The primers for the assessment of the expression levels of the osteogenic markers ALP and OPN and inflammatory markers TNF- $\alpha$ and IL-10 were designed using DNA sequences for these genes available from NCBI (https://www.ncbi.nlm.nih.gov/nuccore), employing PRIMER3plus software tool (http://www.bioinformatics.nl/cgibin/primer3plus/primer3plus.cgi) and are listed on Table 2.

Table 2. Primer sequences for qRT-PCR.

\begin{tabular}{|c|c|c|}
\hline Gene & Forward sense & Reversed sense \\
\hline GADPH & TGCCCCCATGTTTGTGATG & TGGTGGTGCAGGATGCATT \\
\hline ALP & CCAGCAGGTTTCTCTCTTGG & CTGGGAGTCTCATCCTGAGC \\
\hline OPN & TGGAACTTGCTTGACTATCGA & GACCACATGGACGACGATG \\
\hline TNF- $\alpha$ & AGCCCCCAGTCTGTATCCTT & CTCCCTTTGCAGAACTCAGG \\
\hline IL-10 & CCAAGCCTTATCGGAAATGA & TTTTCACAGGGGAGAAATCG \\
\hline
\end{tabular}

cDNA obtained from each MC3T3-E1 culture corresponding to each material was used for RT-qPCR with the ALP and OPN primers, to evaluate osteogenic induction. The TNF$\alpha$ and IL-10 primers were used to assess inflammation expression levels in the RAW 264.7 cell culture. All primers are listed from $5^{\prime}$ to $3^{\prime}$. GADPH was used as a housekeeping gene to normalize the data obtained from the RT-qPCR and calculate the relative fold-change between conditions. qPCR reactions were carried out using SYBR PREMIX Ex Taq (Tli RNase H Plus; TAKARA Bio Inc.), in an Applied Biosystems StepOne Plus ${ }^{\mathrm{TM}}$ Real-Time PCR System (Foster City, California, USA). The cycling parameters were an initial denaturation step at $95^{\circ} \mathrm{C}$ for $30 \mathrm{~s}$ followed by $95^{\circ} \mathrm{C}$ for $5 \mathrm{~s}$ 
and $60{ }^{\circ} \mathrm{C}$ for $34 \mathrm{~s}$, for 40 cycles. The final melt curve stage comprised a cycle at $95{ }^{\circ} \mathrm{C}$ for $15 \mathrm{~s}$ and at $60{ }^{\circ} \mathrm{C}$, for $60 \mathrm{~s}$.

\subsubsection{Cytokine quantification}

The ELISA kits for TNF- $\alpha$ (Thermo Fisher Scientific) were employed to quantify the proteins produced by RAW 264.7 cells cultured on each of the materials tested (following manufacturer's instructions).

\subsubsection{Statistical analysis}

Data were submitted to one-way analysis of variance (ANOVA) and to a Newman-Keuls multiple comparison post-test, when appropriate. Differences with $\mathrm{p} \leq 0.05$ were considered statistically significant.

\subsection{Adsorbed protein layer}

Ca-doped and non-doped sol-gel biomaterials were incubated in a 24-well plate for 180 min in a humidified atmosphere $\left(37^{\circ} \mathrm{C}, 5 \% \mathrm{CO}_{2}\right)$, after the addition of $1 \mathrm{~mL}$ of human blood serum from male AB plasma (Sigma-Aldrich). The serum was removed, and, to eliminate the non-adsorbed proteins, the discs were rinsed five times with $\mathrm{ddH}_{2} \mathrm{O}$ and once with $100 \mathrm{mM} \mathrm{NaCl}, 50 \mathrm{mM}$ Tris- $\mathrm{HCl}, \mathrm{pH}$ 7.0. The adsorbed protein layer was collected by washing the discs in $0.5 \mathrm{M}$ triethylammonium bicarbonate buffer (TEAB) with $4 \%$ of sodium dodecyl sulfate and $100 \mathrm{mM}$ of dithiothreitol (DTT). Four independent experiments were carried out for each type of surface; in each experiment, four discs for each material were processed. The serum protein content was quantified before the experiment (Pierce BCA assay kit; Thermo Fisher Scientific), obtaining a value of $49 \mathrm{mg} \mathrm{mL}^{-1}$. 


\subsection{Proteomic analysis}

Proteomic analysis was performed as described by Romero-Gavilán et al. [17], with minor variations. Briefly, the eluted protein was digested in-solution, following the FASP protocol established by Wisnewski et al. [25], and loaded onto a nanoACQUITY UPLC system connected online to an SYNAPT G2-Si MS System (Waters, Milford, MA, USA). Each material was analyzed in quadruplicate. Differential protein analysis was carried out using Progenesis software (Nonlinear Dynamics, Newcastle, UK) as described before [17], and the functional annotation of the proteins was performed using DAVID Go annotation program (https://david.ncifcrf.gov/) and Panther classification system (http://www.pantherdb.org/).

\section{Results}

\subsection{Synthesis and physicochemical characterization}

The sol-gel material was successfully synthesized, and well-adhering coatings were deposited on the Ti substrate (Fig. 1). The incorporation of small amounts of calcium salt resulted in homogeneous coatings. However, when more than $2.5 \%$ of $\mathrm{CaCl}_{2}$ was added to the sol-gel, some craters were observed in the coatings, likely due to the dehydration process in the network during the heating treatment. Nevertheless, no $\mathrm{CaCl}_{2}$ precipitates were detected in any of the cases (calcium salt was homogeneously distributed in the solgel network). The coatings covered the initial roughness associated with the previous SAE treatment. In consequence, a decrease in Ra was observed (Fig. 1h). 

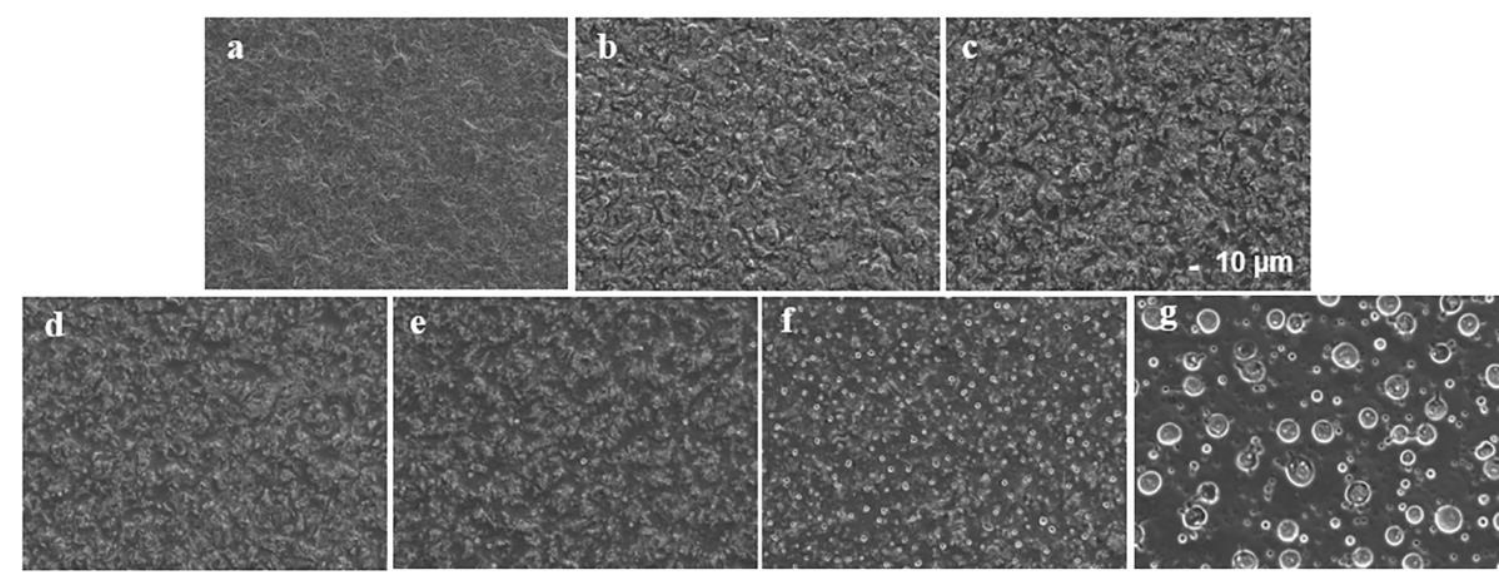

h

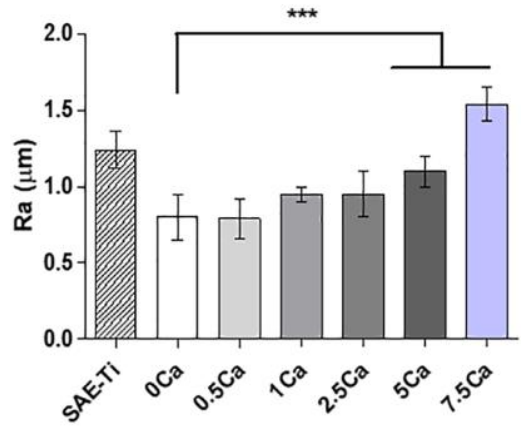

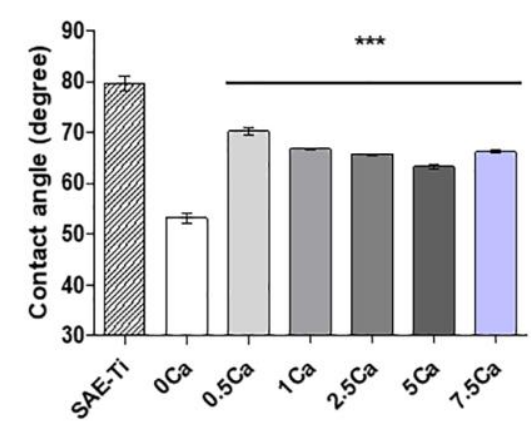

Fig. 1. SEM microphotograph of SAE-Ti (a), $0 \mathrm{Ca}(\mathrm{b}), 0.5 \mathrm{Ca}(\mathrm{c}), 1 \mathrm{Ca}(\mathrm{d}), 2.5 \mathrm{Ca}(\mathrm{e}), 5 \mathrm{Ca}$ (f) and 7.5Ca (g). Scale bar, $10 \mu \mathrm{m}$. Roughness (h) and contact angle (i) results. Bars indicate standard deviations. One-way ANOVA with a Kruskal-Wallis post-test was used to perform the statistical analysis $(* * *, p<0.001)$. Significance levels are relative to the 0Ca base material.

The incorporation of small amounts of $\mathrm{CaCl}_{2}$ did not cause significant changes in $\mathrm{Ra}$ in comparison with the base composition. However, Ra increased significantly on 5Ca and 7.5Ca surfaces, probably as a consequence of crater formation. Fig. 1i displays the contact angle measurements. The sol-gel base material was more hydrophilic than the SAE-Ti surface, with a decrease in contact angle of approximately $30^{\circ}$. The addition of $\mathrm{CaCl}_{2}$ to this base material caused a significant increase in the contact angle, reaching the values of approximately $65^{\circ}$. 


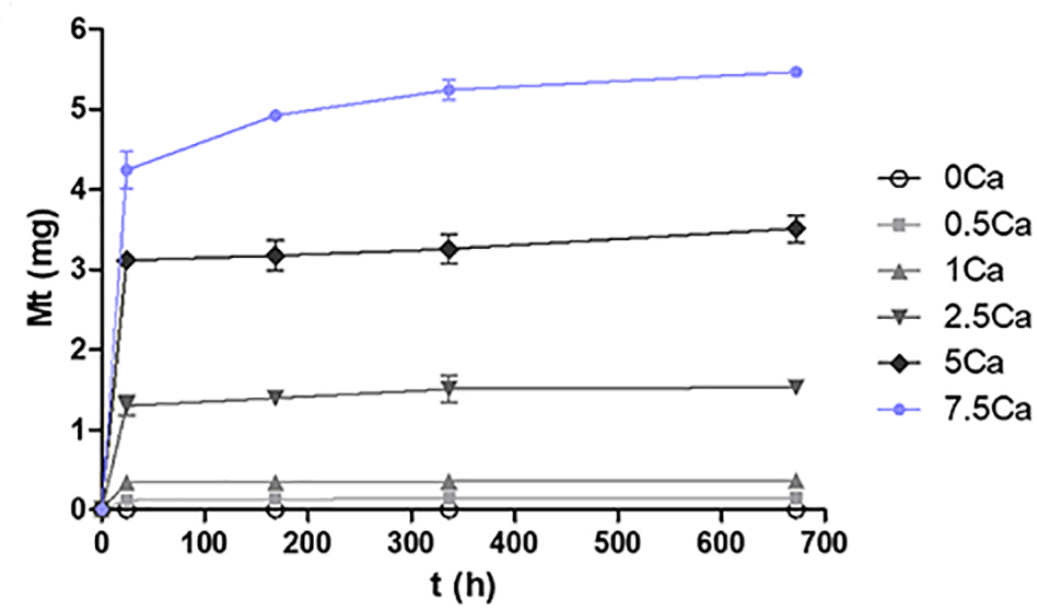

Fig. 2. Kinetic liberation of $\mathrm{Ca}^{2+}$ from the coatings. Mt represents the total amount of $\mathrm{Ca}^{2+}$ release from the sol-gel network during time.

Fig. 2 shows the liberation of $\mathrm{Ca}^{2+}$ ions released by the network during time. It is clear that with the addition of increasing quantities of $\mathrm{CaCl}_{2}$ to the network there is higher release of $\mathrm{Ca}^{2+}$ ions, as expected. Moreover, all the materials show a fast inicial release during the first $24 \mathrm{~h}$; after this time, it is observable a constant and steady liberation the next 27 days. This fact is clearer for higher concentrations of $\mathrm{Ca}$.

\subsection{In vitro assay - $m R N A$ expression levels}

The expression of osteogenic markers is displayed in Fig. 3a and b. ALP gene expression levels show a tendency to increase after 14 days, with highest values for the formulation 1Ca (decreasing for the higher $\mathrm{Ca}$ concentrations). As expected, the hybrid sol-gel silica material affects the expression of this gene (Fig. 3a).

The OPN expression decreases on the compositions $0.5 \mathrm{Ca}$ and $1 \mathrm{Ca}$ at 7 days of culture; after 14 days, upregulation of this gene is observed in comparison with the base material with no calcium in its network 0Ca (Fig. 3b). 
The expression of immune response genes TNF- $\alpha$ and IL-10 increases on the materials supplemented with calcium when compared with the base material (Fig. 3c and d).
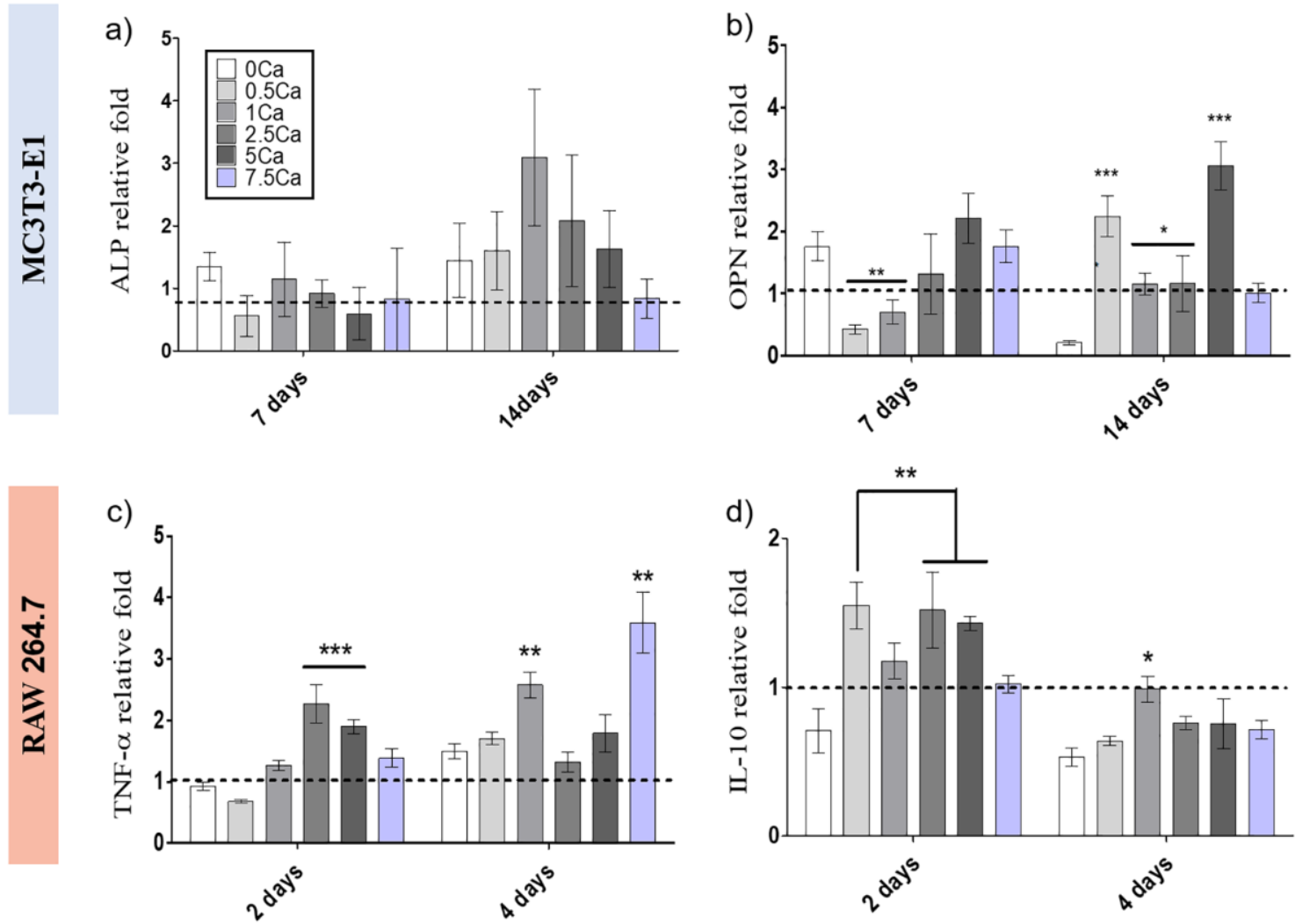

Fig. 3. Relative gene expression levels of osteogenic markers a) ALP and b) OPN in the MC3T3-E1 cells cultured on the different tested Ca formulations after 7 and 14 days of culture. Relative gene expression levels of the inflammatory markers c) TNF- $\alpha$ and d) IL10 in the RAW 264.7 cells cultured on the different formulations after 2 and 4 days of culture. The relative mRNA expression was determined by qRT-PCR Statistical analysis was performed using one-way ANOVA with a Kruskal-Wallis post-test $(*, \mathrm{p}<0.05$; **, $\mathrm{p}<0.01 ; * * *, \mathrm{p}<0.001) .1$-Fold represents the basal expression of cells with no disc (dashed line). Significant difference levels are for the comparisons with the base material (0Ca).

Fig. 4 shows the TNF- $\alpha$ release after RAW 264.7 cell incubation with the different formulations. There is a significant decrease in the release of this protein for the materials 
with lower concentrations of $\mathrm{Ca}(0.5 \mathrm{Ca}$ and $1 \mathrm{Ca})$. However, an increase was observed in the release of TNF- $\alpha$ from the cells on 5Ca coatings (significant after 4 days of culture).

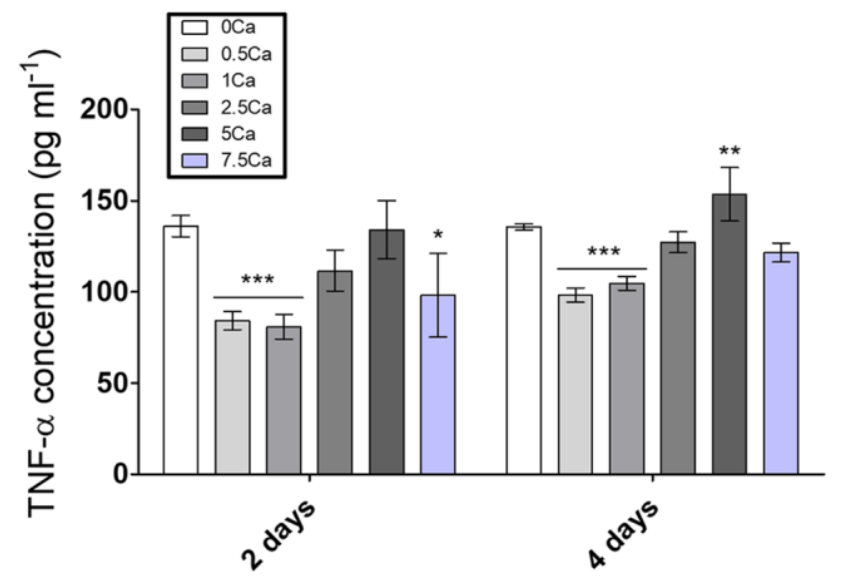

Fig. 4. TNF- $\alpha$ cytokine expression in RAW 264.7 macrophages at 2-day and 4-day time points. Statistical analysis was performed using one-way ANOVA with a Kruskal-Wallis post-test $(*, \mathrm{p}<0.05 ; * *, \mathrm{p}<0.01 ; * * *, \mathrm{p}<0.001)$. Significant differences are relative to the results for the base material $(0 \mathrm{Ca})$.

\subsection{Proteomic analysis}

The eluates of the proteins attached to the sol-gel coatings were analyzed using the LCMS/MS; 113 distinct proteins were identified. Statistical comparisons between the results for Ca-enriched compositions and the base sol-gel material (0Ca) were performed using the Progenesis QI software. DAVID and Panther databases were used to obtain functional protein classification.

The Progenesis comparative analysis showed some differences between the patterns of proteins adsorbed on calcium-enriched materials and the reference material. The analysis revealed 45 differentially adsorbed proteins. Twenty-two of these proteins were more abundant on the surfaces of the Ca-doped biomaterials than to the reference surfaces (Table S1). The remaining 23 proteins showed reduced affinity to Ca-doped surfaces; the 
amounts adsorbed on these materials decreased in comparison with the controls (Table S2).

Among the 22 proteins with increased adsorption, several were associated with the immune system (SAMP, C4BPA, CLUS, C1QC, and KV302 immunoglobulin). The adsorption of SAMP increased 13.8-fold on the 7.5Ca-supplemented formulation in comparison with the reference material. However, the adsorption of some other proteins related to immunity processes (immunoglobulins LV301, LAC2, IGLL5, and IGHA and FHR2) was reduced on the Ca-doped surfaces.

Apolipoproteins APOA4, APOA5, APOC4, APOE, and APOL1 and the high-density apolipoprotein SAA4 were more abundant on the materials with $\mathrm{Ca}$, while APOA2, APOB, APOC1, APOC3, and APOD showed reduced affinity to these surfaces. All these apolipoproteins have functions related to the lipoprotein metabolic processes and phospholipid binding.

DAVID analysis revealed that THRB, ANT3, PROS, PROC, A2AP, and A2MG are proteins with important functions in the blood coagulation system. These proteins had increased affinity to the Ca-supplemented coating formulations. However, the abundance of KNG1, also linked to coagulation functions, was reduced on the 1Ca coating.

The glycoproteins VTNC and SEPP1 were predominantly found on the Ca-doped materials, while DSC1, A1AG1, A1AG2, SPF4V, and ITIH4 glycoproteins had reduced affinity to these surfaces. The amounts of HEMO, KCRM, and ANGT adhering to the materials with calcium increased in comparison with controls. In contrast, ANXA2, A2G2, S10A7, GELS, VTDB, and TGM3 showed a higher affinity to the reference base material $0 \mathrm{Ca}$. The proteins in this last group have, among others, some binding functions. 
Fig. 5 shows the Ca content-dependent changes in the abundance of main preferentially adsorbed proteins involved in bone regenerative processes.
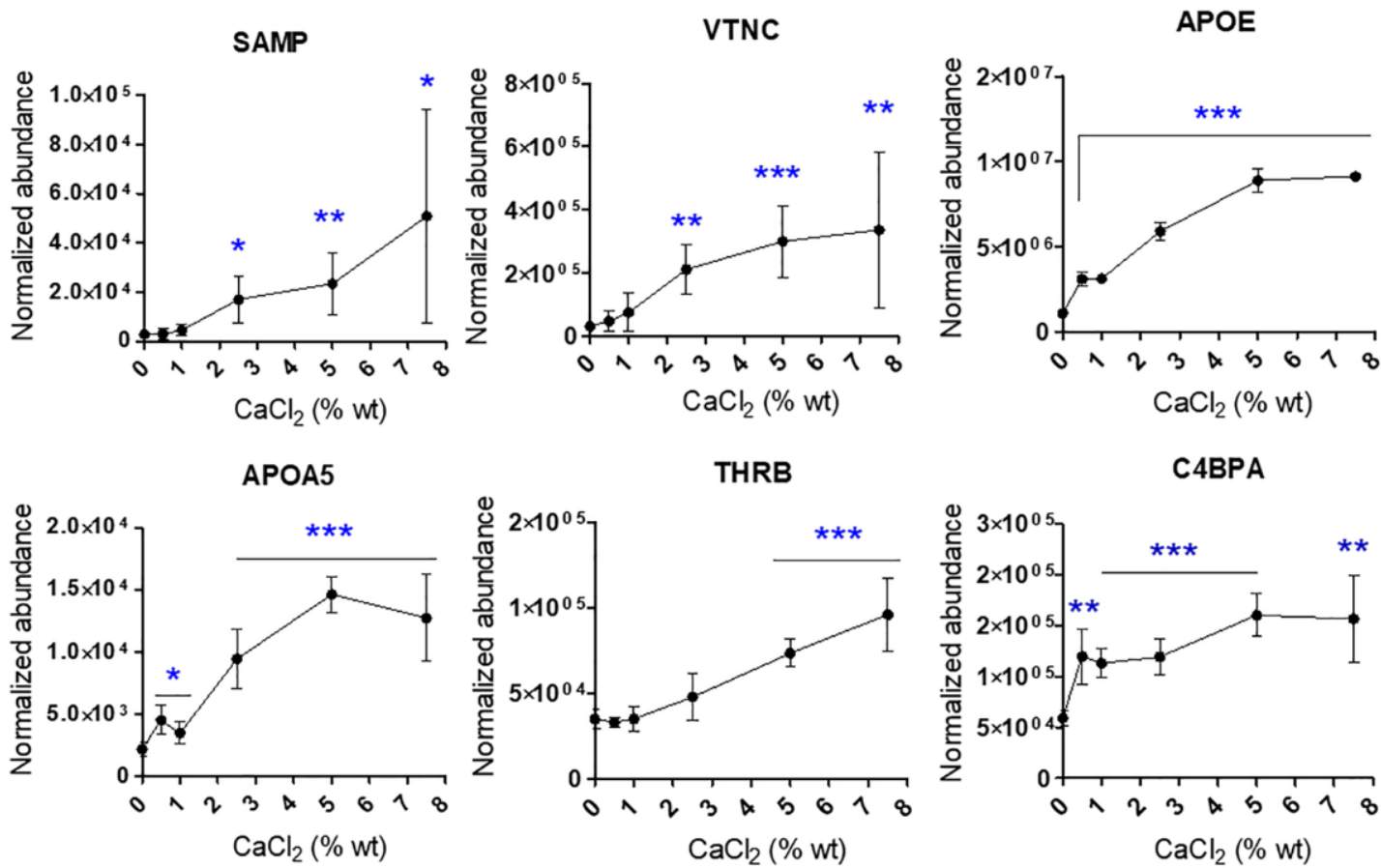

ANT3

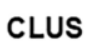

PROS
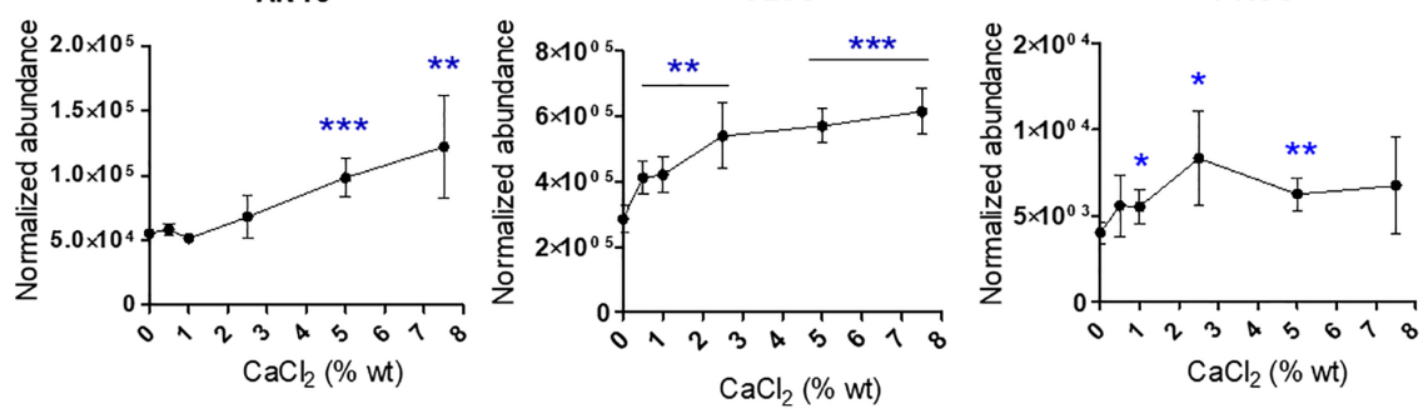

Fig. 5. The normalized abundance of 9 proteins with more affinity to Ca-enriched coatings, in comparison with the base material (ANOVA: *, p < 0.05; **, p < 0.01; ***, $\mathrm{p}<0.001)$

Panther analysis was used to find the involvement of the differentially adsorbed proteins in biological processes and pathway functions. The pie-chart diagrams in Fig. 6 display biological processes associated with the proteins differentially attached (increased or reduced affinity in comparison with the reference sample $0 \mathrm{Ca}$ ) to $0.5 \mathrm{Ca}$ and $7.5 \mathrm{Ca}$ 
coatings. Since the patterns were common for calcium-doped samples, with hardly any differences, only the data for the boundary concentrations are displayed. Some functions related to cellular, metabolic, and developmental processes were identified. The comparison of the functions characteristic for differentially adhering protein groups showed that the proteins with increased affinity to Ca-coatings were implicated in more biological processes than those with the reduced affinity. The biological adhesion, multicellular organismal and immune system functions were associated only with the former (enhanced adherence) group. On the whole, the incorporation of $\mathrm{CaCl}_{2}$ in the solgel material increases the adherence of proteins associated with the coagulation pathway, as shown in Fig. 7.
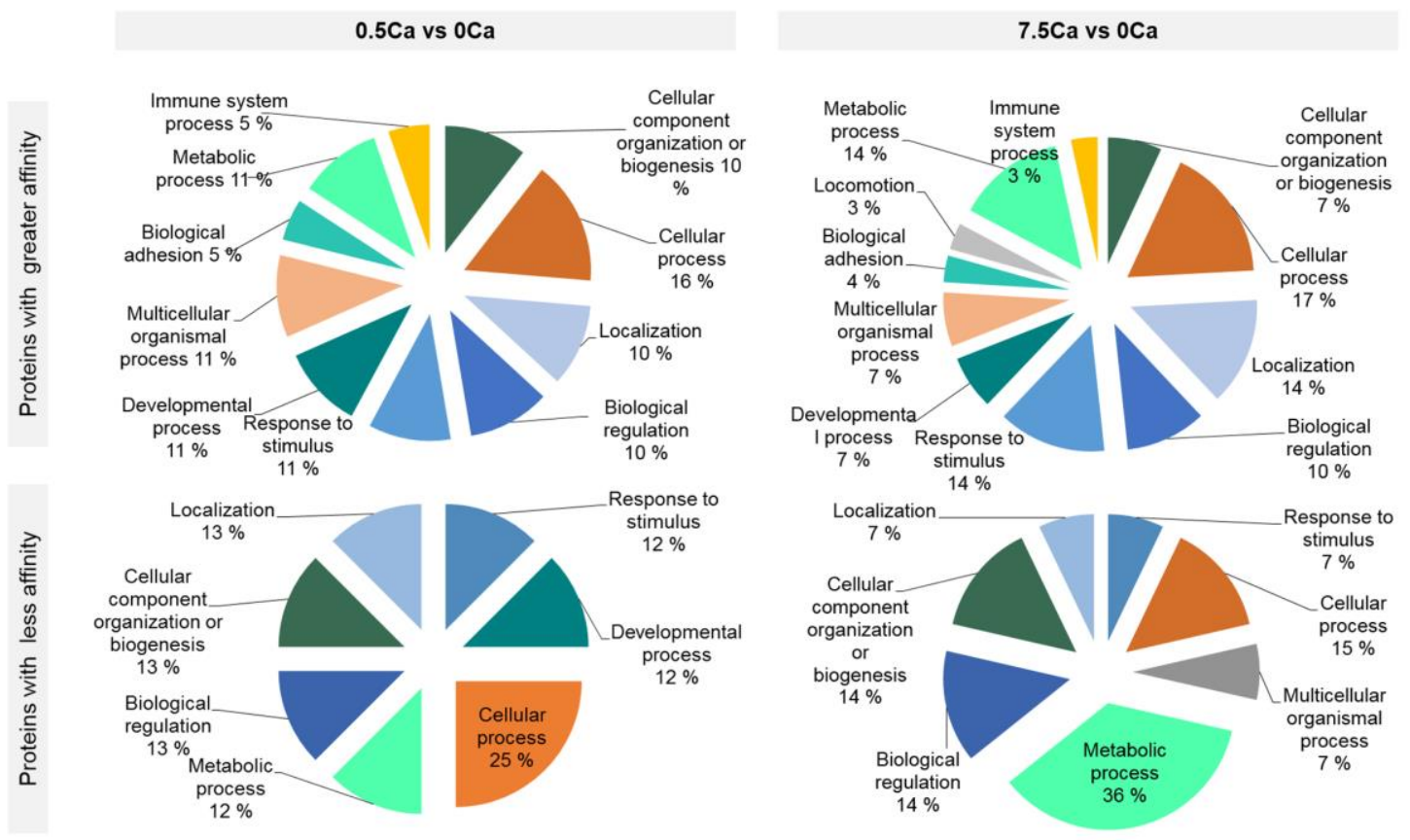

Fig. 6. PANTHER diagram showing biological functions of the proteins differentially adhering onto $0.5 \mathrm{Ca}$ and $7.5 \mathrm{Ca}$ in comparison with the reference sample $(0 \mathrm{Ca})$. 


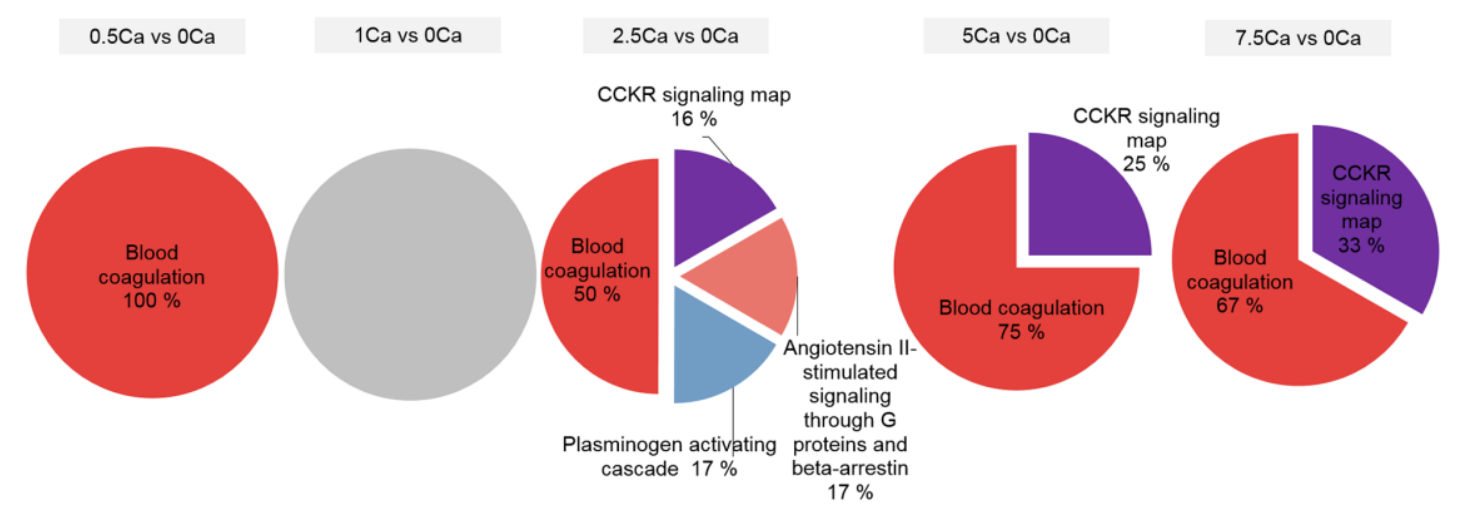

Fig. 7. PANTHER diagram with the pathway functions of the proteins with increased adherence to Ca-enriched sol-gel coatings in comparison with the reference sample $(0 \mathrm{Ca})$.

\section{Discussion}

Many macro- and micro-nutrients have been studied in search of new methods to improve the recovery after surgical interventions involving bone implants. Among those nutrients, calcium has attracted considerable attention as it is one of the structural elements in the mineral bone phase, and, thus, has a key role in bone metabolism [26]. The aim of this study was to examine the effect of this element on the protein-biomaterial interactions.

The incorporation of $\mathrm{CaCl}_{2}$ into the $35 \mathrm{M} 35 \mathrm{G} 30 \mathrm{~T}$ base material introduces, apart from the obvious chemical changes, modifications in surface properties such as roughness and wettability (Fig. 1h and 1i). The contact angle significantly increases when the calcium salt is incorporated into the sol-gel network, in comparison with the base material (reaching moderate hydrophilic values around $65^{\circ}$ ). The roughness parameter $\mathrm{Ra}$ increases for both $5 \mathrm{Ca}$ and 7.5Ca materials when compared to 0Ca. The kinetic liberation studies display that $\mathrm{Ca}$ is present on the network, with a controlled release, detected even after 28 days of immersion in water. These physicochemical changes modify the tissuebiomaterial interface. Such changes will also affect the protein attachment, thus conditioning the microenvironment in which the tissue repair occurs. 
At the cellular level, $\mathrm{Ca}^{2+}$ has a stimulatory effect on the osteoblasts, promoting their proliferation and differentiation. Indeed, the treatment with $\mathrm{CaCl}_{2}$ can enhance the osteogenesis of stem cells [6]. Here, we observed that ALP gene expression (an osteogenesis marker) tends to increase during the 14 days of incubation with Ca-doped materials, with the highest values for $1 \mathrm{Ca}$ formulation (Fig. 3a). The macrophage expression of the TNF- $\alpha$ gene increased in a $\mathrm{Ca}$ dose-dependent manner after 2 and 4 days of incubation on Ca-supplemented coatings in comparison with the 0Ca base material. Similarly, the macrophages increased their IL-10 gene expression, even for the lowest $\mathrm{Ca}$ concentration $(0.5 \mathrm{Ca})$. IL-10 is said to have an anti-inflammatory role and is known as a marker for M2 macrophages, a pro-regenerative phenotype [19]. These data were consistent with the ELISA results, which showed that the low $\mathrm{Ca}$ doses $(0.5 \mathrm{Ca}$ and $1 \mathrm{Ca}$ ) decreased the release of TNF- $\alpha$, thus reducing the inflammatory response in comparison with the base material. In contrast, some other $\mathrm{Ca}$ formulations stimulate the production of inflammatory markers $(5 \mathrm{Ca})$.

The LC-MS/MS characterization of protein layers deposited onto different Ca-enriched coatings detected 113 proteins. The Progenesis comparative analysis identified some changes in their adsorption patterns, dependent on the amount of $\mathrm{CaCl}_{2}$ incorporated into the coating material. Varying results were obtained for different apolipoproteins. APOA4, APOA5, APOC4, APOE, APOL1, and SAA4 increased their affinity to the biomaterials containing $\mathrm{CaCl}_{2}$. However, the abundance of APOA2, APOB, APOC1, APOC3, and APOD decreased on some of these surfaces. Apart from its known functions in lipid metabolism, this protein family might also play a role in preventing the initiation of innate immune response [27]. Meerasa et al. [28] have found that the preferential attachment of lipoproteins on a material could reduce the complement system activation. It is difficult to form a clear general picture of the effect of $\mathrm{Ca}$ on apolipoprotein adsorption as two 
opposing tendencies were observed. Some apolipoproteins decreased their affinity to the coatings with 5Ca composition. However, APOA5 and APOE were preferentially adsorbed onto the Ca-enriched coatings, beginning with the lowest $\mathrm{Ca}$ content $(0.5 \mathrm{Ca})$, reaching abundance ratios $(\mathrm{Ca}-\mathrm{doped} / 0 \mathrm{Ca})$ of 5.8 and 8.3 , respectively, for the $7.5 \mathrm{Ca}$ composition. The significant increase in the APOE affinity to the Ca-coatings might be important since this protein can promote macrophage polarization from its proinflammatory M1 to the reparative M2 phenotype, showing an anti-inflammatory effect [29].

APOE has also been described as a protein essential for bone metabolism due to its involvement in the vitamin $\mathrm{K}$ uptake by the osteoblasts [30]. Moreover, it can inhibit osteoclastic differentiation by suppressing RANKL-dependent activation of nuclear factor кd ligand and induction of C-Fos and nuclear factor of activated T cells c1 [31].

The adsorption of pentraxin SAMP onto the coatings rose with the increasing $\mathrm{CaCl}_{2}$ content. This is consistent with its structure; this glycoprotein consists of five subunits, each containing two $\mathrm{Ca}^{2+}$ binding positions [32]. The interactions between SAMP and other proteins and molecules are also dependent on $\mathrm{Ca}^{2+}$ concentration [33]. Although the SAMP function is still unclear, it is associated with inflammation, tissue remodeling and coagulation processes [34]. C1QC (serum complement subcomponent C1q), whose adsorption was enhanced only on the 5Ca material, is directly involved in the complement system activation through the classical pathway [33]. The increased adhesion of C1QC to this specific formulation might be related to the enhanced inflammatory response observed in the in vitro experiments. The addition of $\mathrm{CaCl}_{2}$ to the coatings resulted in a decrease in immunoglobulin adsorption; the relative abundance of LV301, LAC2, IGHG4, IGLL5, and IGHA2 on these materials was reduced, only KV302 increased its affinity (to 2.5Ca). C4BPA and CLUS showed enhanced adsorption to the Ca-enriched 
materials. These two proteins are complement cascade inhibitors, restricting the pathway activation by regulating its intensity [35]. They modulate the immune/inflammatory response to achieve the correct tissue regeneration [19]. Panther analysis did not find many immune functionalities among the proteins differentially adsorbed to Ca-materials; the proportion of the proteins involved in immune functions was only moderate, i.e., $5 \%$ and $3 \%$ for $0.5 \mathrm{Ca}$ and $7.5 \mathrm{Ca}$, respectively (Fig. 6). This might mean that the incorporation of $\mathrm{CaCl}_{2}$ in sol-gel should not result in immune problems, at least from the proteomic perspective.

One of the key processes in bone tissue regeneration is blood coagulation. This process is initiated after implantation, as a consequence of the injury. Besides its osteogenic role, $\mathrm{Ca}$ ions are also associated with blood clotting. It has been reported that $\mathrm{CaCl}_{2}$ modulates blood clot formation and stability in a dose-dependent manner [36]. The Ca-networks might also boost the coagulation pathway activities as suggested by the specific adsorbed proteins identified by Panther: THRB, ANT3, PROS, PROC, A2AP, and A2MG (Fig. 7). After an injury, the coagulation cascade is activated, leading to blood clotting. During this process, THRB undergoes a succession of transformations, with thrombin as a final product, whose interaction with fibrinogen triggers the fibrin clot formation $\mathrm{The}^{\mathrm{Ca}^{2+}}$ ions and phospholipids are cofactor intermediators in this process [37]. Nevertheless, excessive activation of coagulation could trigger thrombotic and acute inflammatory reactions [38]. The increased deposition of ANT3, PROS, or PROC might control this process. Both PROS and PROC are involved in the regulation of the coagulation pathway, inactivating factor Va and VIIIa and then controlling thrombin generation [39]. Similarly, ANT3 might regulate thrombin formation through the inhibition of FIIa and FXa [40]. A2MG can suppress serine proteinases in the plasma by inhibiting thrombin, kallikrein, and plasmin. Biltoft et al. [41] have proposed that the A2MG found on artificial surfaces 
could serve as a global marker of biomaterial blood compatibility. However, Cvirn et al. [42] have reported that this protein displays both procoagulant and anticoagulant functions depending on the levels of antithrombin.

In contrast, the affinity of high molecular weight type KNG1 was reduced on the $1 \mathrm{Ca}$ and 5Ca coatings. This protein has a role in the intrinsic coagulation pathway, the surfaceactivating coagulation system [43]. After clot formation, the fibrinolysis causes fibrin degradation, driving correct tissue repair. This process depends on the outcome of coagulation and its resulting clot structure. A2AP, with its increased adsorption to the $2.5 \mathrm{Ca}$ coating, is involved in the regulation of this process through the inhibition of plasmin [24].

The glycoprotein VTNC also increased its deposition levels with increasing $\mathrm{CaCl}_{2}$ content in the biomaterials (up to 11.2-fold on 7.5Ca). This protein is known as biological "superglue" and is considered a key controller of the bone tissue repair and remodeling processes. It participates in essential physiological events associated with tissue regeneration. VTNC takes part in establishing the vascular homeostasis and coagulation system by its contribution to thrombus formation [44]. It also interferes in the immune response, regulating the complement cascade activation, in the same way that CLUS and C4BPA [35]. VTNC might also have osteogenic properties as it can promote the osteogenic differentiation of mesenchymal stem cells [45]. These properties are consistent with the results of Cacchioli et al. [46] who have found that the attachment of human VTNC peptides to titanium implant surfaces improves the in vivo osteointegration of the implant. 


\section{Conclusion}

In conclusion, the addition of $\mathrm{CaCl}_{2}$ to the silica sol-gel coatings increases their osteogenic potential in vitro, at the same time affecting inflammatory processes in a dose-dependent manner. The proteomic characterization revealed changes in the adsorption patterns of serum proteins, dependent on the content of $\mathrm{CaCl}_{2}$ in the hybrid sol-gel network. Ca-coatings displayed an enhanced affinity for some key pro- and anti-clotting proteins, suggesting an increase in the coagulation potential of these materials. The rise in the relative abundance of APOE and VTNC on the Ca-doped coatings suggests enhanced osteogenic potential of these materials. These results should improve our understanding of biomaterial-protein interactions, especially in the case of Ca-releasing materials.

\section{Acknowledgments}

This work was supported by MINECO [MAT2017-86043-R ]; Universitat Jaume I [grant numbers Predoc/2014/25, UJI-B2017-37]; Basque Government [grant numbers IT61113, Predoc/2016/1/0141]; University of the Basque Country [grant number UFI11/56]. CIC bioGUNE is supported by Basque Department of Industry, Tourism and Trade (Etortek and Elkartek programs), the Innovation Technology Department of the Bizkaia County; The ProteoRed-ISCIII (Grant PRB3 IPT17/0019); CIBERehd Network, and Severo Ochoa Grant (SEV-2016-0644). Authors would like to thank Antonio Coso and Jaime Franco (GMI-Ilerimplant) for their inestimable contribution to this study, and Raquel Oliver, Jose Ortega (UJI), René van Rheden (Radboudumc), Vicent Cuijpers (Radboudumc), and Iraide Escobes (CIC bioGUNE) for their valuable technical assistance. 


\section{References}

1. Berridge MJ, Bootman MD, Lipp P (1998) Calcium - a life and death signal. Nature 395:645-648. https://doi.org/10.1038/27094

2. Hoppe A, Güldal NS, Boccaccini AR (2011) A review of the biological response to ionic dissolution products from bioactive glasses and glass-ceramics. Biomaterials 32:2757-2774. https://doi.org/10.1016/j.biomaterials.2011.01.004

3. Flynn A (2003) The role of dietary calcium in bone health. Proc Nutr Soc 62:851-858. https://doi.org/10.1079/PNS2003301

4. Marie PJ (2010) The calcium-sensing receptor in bone cells: A potential therapeutic target in osteoporosis. Bone 46:571-576. https://doi.org/10.1016/j.bone.2009.07.082

5. Honda Y, Fitzsimmons RJ, Baylink DJ, Mohan S (1995) Effects of extracellular calcium on insulin-like growth factor II in human bone cells. J bone Miner Res 10:1660-5. https://doi.org/10.1002/jbmr.5650101108

6. Koori K, Maeda H, Fujii S, et al (2014) The roles of calcium-sensing receptor and calcium channel in osteogenic differentiation of undifferentiated periodontal ligament cells. Cell Tissue Res 357:707-718. https://doi.org/10.1007/s00441014-1918-5

7. Habibovic P, Barralet JE (2011) Bioinorganics and biomaterials: Bone repair. Acta Biomater 32:3013-3026. https://doi.org/10.1016/j.actbio.2011.03.027

8. Oshiro Junior J, Paiva Abuçafy M, Berbel Manaia E, et al (2016) Drug Delivery Systems Obtained from Silica Based Organic-Inorganic Hybrids. Polymers (Basel) 8:91. https://doi.org/10.3390/polym8040091

9. Jones JR (2015) Reprint of: Review of bioactive glass: From Hench to hybrids. Acta Biomater 23:S53-S82. https://doi.org/10.1016/j.actbio.2015.07.019

10. Romero-Gavilán F, Barros-Silva S, García-Cañadas J, et al (2016) Control of the degradation of silica sol-gel hybrid coatings for metal implants prepared by the triple combination of alkoxysilanes. J Non Cryst Solids 453:66-73. https://doi.org/10.1016/j.jnoncrysol.2016.09.026

11. Martínez-Ibáñez M, Juan-Díaz MJ, Lara-Saez I, et al (2016) Biological characterization of a new silicon based coating developed for dental implants. J Mater Sci Mater Med 27:80. https://doi.org/10.1007/s10856-016-5690-9

12. Martínez-Ibáñez M, Murthy NS, Mao Y, et al (2018) Enhancement of plasma protein adsorption and osteogenesis of hMSCs by functionalized siloxane coatings for titanium implants. J Biomed Mater Res - Part B Appl Biomater 106:1138-1147. https://doi.org/10.1002/jbm.b.33889

13. Salinas AJ, Merino JM, Babonneau F, et al (2007) Microstructure and Macroscopic Properties of Bioactive CaO-SiO2-PDMS Hybrids. J Biomed Mater Res B Appl Biomater 81B:274-82. https://doi.org/10.1002/jbm.b.30663

14. Almeida JC, Wacha A, Gomes PS, et al (2016) A biocompatible hybrid material with simultaneous calcium and strontium release capability for bone tissue repair. 
Mater Sci Eng C 62:429-438. https://doi.org/10.1016/j.msec.2016.01.083

15. Valliant EM, Romer F, Wang D, et al (2013) Bioactivity in silica/poly(c-glutamic acid) sol-gel hybrids through calcium chelation. Acta Biomater 9:7662-7671. https://doi.org/10.1016/j.actbio.2013.04.037

16. Shirosaki Y, Tsuru K, Hayakawa S, et al (2005) In vitro cytocompatibility of MG63 cells on chitosan-organosiloxane hybrid membranes. Biomaterials 26:485-493. https://doi.org/10.1016/j.biomaterials.2004.02.056

17. Romero-Gavilán F, Gomes NC, Ródenas J, et al (2017) Proteome analysis of human serum proteins adsorbed onto different titanium surfaces used in dental implants. Biofouling 33:98-111. https://doi.org/10.1080/08927014.2016.1259414

18. Hirsh SL, McKenzie DR, Nosworthy NJ, et al (2013) The Vroman effect: Competitive protein exchange with dynamic multilayer protein aggregates. Colloids Surfaces B Biointerfaces 103:395-404. https://doi.org/10.1016/j.colsurfb.2012.10.039

19. Chen Z, Klein T, Murray RZ, et al (2015) Osteoimmunomodulation for the development of advanced bone biomaterials. Mater Today 19:304-321. https://doi.org/10.1016/j.mattod.2015.11.004

20. Araújo-Gomes N, Romero-Gavilán F, García-Arnáez I, et al (2018) Osseointegration mechanisms: a proteomic approach. J Biol Inorg Chem 23:459470. https://doi.org/10.1007/s00775-018-1553-9

21. Romero-Gavilán F, Sanchez-Pérez AM, Araújo-Gomes N, et al (2017) Proteomic analysis of silica hybrid sol-gel coatings: a potential tool for predicting the biocompatibility of implants in vivo. Biofouling 33:676-689. https://doi.org/10.1080/08927014.2017.1356289

22. Araújo-Gomes N, Romero-Gavilán F, Sanchez-Pérez AM, et al (2018)

Characterization of serum proteins attached to distinct sol-gel hybrid surfaces. J Biomed Mater Res - Part B Appl Biomater 106:1477-1485. https://doi.org/10.1002/jbm.b.33954

23. Romero-Gavilan F, Araújo-Gomes N, Sánchez-Pérez AM, et al (2017) Bioactive potential of silica coatings and its effect on the adhesion of proteins to titanium implants. Colloids Surfaces B Biointerfaces 162:316-325. https://doi.org/10.1016/j.colsurfb.2017.11.072

24. Shiu HT, Goss B, Lutton C, et al (2014) Formation of blood clot on biomaterial implants influences bone healing. Tissue Eng - Part B Rev 20:697-712. https://doi.org/10.1089/ten.teb.2013.0709

25. Wisniewski JR, Zougman A, Nagaraj N, Mann M (2009) Universal sample preparation method for proteome analysis. Nat Methods 6:3-8. https://doi.org/10.1038/NMETH.1322

26. Dvorak MM, Riccardi D (2004) Ca2+as an extracellular signal in bone. Cell Calcium 35:249-255. https://doi.org/10.1016/j.ceca.2003.10.014

27. Cho NH, Seong SY (2009) Apolipoproteins inhibit the innate immunity activated by necrotic cells or bacterial endotoxin. Immunology 128:479-486.

https://doi.org/10.1111/j.1365-2567.2008.03002.x 
28. Meerasa A, Huang JG, Gu FX (2013) Human serum lipoproteins influence protein deposition patterns on nanoparticle surfaces. ACS Appl Mater Interfaces 5:489-493. https://doi.org/10.1021/am302554q

29. Baitsch D, Bock HH, Engel T, et al (2011) Apolipoprotein e induces antiinflammatory phenotype in macrophages. Arterioscler Thromb Vasc Biol 31:1160-8. https://doi.org/10.1161/ATVBAHA.111.222745

30. Niemeier A, Schinke T, Heeren J, Amling M (2012) The role of Apolipoprotein $\mathrm{E}$ in bone metabolism. Bone 50:518-524. https://doi.org/10.1016/j.bone.2011.07.015

31. Kim WS, Kim HJ, Lee ZH, et al (2013) Apolipoprotein E inhibits osteoclast differentiation via regulation of c-Fos, NFATc1 and NF- $\kappa$ B. Exp Cell Res 319:436-446. https://doi.org/10.1016/j.yexcr.2012.12.004

32. Emsley J, White HE, O'Hara BP, et al (1994) Structure of pentameric human serum amyloid $\mathrm{P}$ component. Nature 367:338-45

33. Poulsen ET, Pedersen KW, Marzeda AM, Enghild JJ (2017) Serum Amyloid P Component (SAP) Interactome in Human Plasma Containing Physiological Calcium Levels. Biochemistry 56:896-902. https://doi.org/10.1021/acs.biochem.6b01027

34. Bottazzi B, Inforzato A, Messa M, et al (2016) The pentraxins PTX3 and SAP in innate immunity, regulation of inflammation and tissue remodelling. J Hepatol 64:1416-1427. https://doi.org/10.1016/j.jhep.2016.02.029

35. Mollnes TE, Kirschfink M (2006) Strategies of therapeutic complement inhibition. Mol Immunol 43:107-121. https://doi.org/10.1016/j.molimm.2005.06.014

36. Gessmann J, Seybold D, Peter E, et al (2013) Plasma clots gelled by different amounts of calcium for stem cell delivery. Langenbeck's Arch Surg 398:161167. https://doi.org/10.1007/s00423-012-1015-8

37. Scheraga HA (2004) The thrombin-fibrinogen interaction. Biophys Chem 112:117-130. https://doi.org/10.1016/j.bpc.2004.07.011

38. Chu AJ (2010) Blood coagulation as an intrinsic pathway for proinflammation: a mini review. Inflamm Allergy Drug Targets 9:32-44. https://doi.org/10.2174/187152810791292890

39. Suleiman L, Négrier C, Boukerche H (2013) Protein S: A multifunctional anticoagulant vitamin K-dependent protein at the crossroads of coagulation, inflammation, angiogenesis, and cancer. Crit Rev Oncol Hematol 88:637-654. https://doi.org/10.1016/j.critrevonc.2013.07.004

40. Furie B, Furie BC (2008) Mechanisms of Thrombus Formation. N Engl J Med 359:938-949. https://doi.org/10.1056/NEJMra0801082

41. Biltoft D, Gram JB, Larsen A, et al (2017) Fast form alpha-2-macroglobulin - A marker for protease activation in plasma exposed to artificial surfaces. Clin Biochem 50:1203-1208. https://doi.org/10.1016/j.clinbiochem.2017.09.002

42. Cvirn G, Gallistl S, Koestenberger M, et al (2002) Alpha 2-macroglobulin 
enhances prothrombin activation and thrombin potential by inhibiting the anticoagulant protein $\mathrm{C} /$ protein $\mathrm{S}$ system in cord and adult plasma. Thromb Res 105:433-439. https://doi.org/10.1016/S0049-3848(02)00042-7

43. Vogler EA, Siedlecki CA (2009) Contact activation of blood-plasma coagulation. Biomaterials 30:1857-1869. https://doi.org/10.1016/j.biomaterials.2008.12.041

44. Leavesley DI, Kashyap AS, Croll T, et al (2013) Vitronectin - Master controller or micromanager? IUBMB Life 65:807-818. https://doi.org/10.1002/iub.1203

45. Kundu AK, Putnam AJ (2006) Vitronectin and collagen I differentially regulate osteogenesis in mesenchymal stem cells. Biochem Biophys Res Commun 347:347-57. https://doi.org/10.1016/j.bbrc.2006.06.110

46. Cacchioli A, Ravanetti F, Bagno A, et al (2009) Human vitronectin-derived peptide covalently grafted onto titanium surface improves osteogenic activity: A pilot in vivo study on rabbits. Tissue Eng - Part A 15:2017-26.

https://doi.org/10.1089/ten.tea.2008.0542 